\begin{tabular}{|c|c|c|c|c|c|c|}
\hline \multirow{4}{*}{ Impact Factor: } & ISRA (India) & $=3.117$ & SIS (USA) & $=0.912$ & ICV (Poland) & $=6.630$ \\
\hline & ISI (Dubai, UAE & $=0.829$ & РИНЦ (Russia) & $=0.156$ & PIF (India) & $=1.940$ \\
\hline & GIF (Australia) & $=0.564$ & ESJI (KZ) & $=8.716$ & IBI (India) & $=4.260$ \\
\hline & JIF & $=1.500$ & SJIF (Morocco) & $=5.667$ & OAJI (USA) & $=0.350$ \\
\hline
\end{tabular}

\section{SOI: $1.1 /$ TAS $\quad$ DOI: $10.15863 /$ TAS International Scientific Journal Theoretical \& Applied Science}

p-ISSN: 2308-4944 (print) e-ISSN: 2409-0085 (online)

Year: 2019 Issue: $05 \quad$ Volume: 73

Published: $22.05 .2019 \quad \underline{\text { http://T-Science.org }}$
QR - Issue

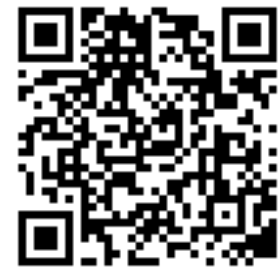

QR - Article

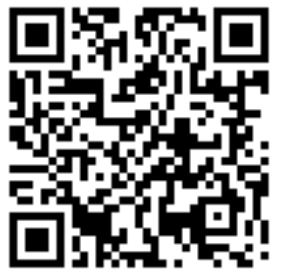

A.S. Seitkaziev

Doctor of Tennis, Professor,

Taraz State University named after M.Kh.Dulati, Taraz adeubai@mail.ru

S.Zh. Salybaev

Candidate of Technical Sciences

Taraz State University named after M.Kh.Dulati, Taraz

K.A. Seitkazieva

$\mathrm{Ph}$ doctoral student

Taraz State University named after M.Kh.Dulati, Taraz

\title{
ESTABLISHMENT OF HYDROCHEMICAL INDICATORS OF SERIOECAL SOILS IN THE SEMI-DUMP ZONE OF THE JAMBYL REGION
}

Abstract: The article discusses the hydrchemical indicators of the soil of the semi-desert zone. To regulate the water-salt regimes in the design layer of the soil and soil, basing on the experimental work on the soil salinity, the salinization standards of the soil have been established.

The hydrochemical parameters of salt transfer in the soil of various mechanical composition were determined.

Key words: hydrochemistry, water-salt soil regime, hydrochemical indicators, filtration, washing norms.

Language: Russian

Citation: Seitkaziev, A. S., Salybaev, S. Z., \& Seitkazieva, K. A. (2019). Establishment of hydrochemical indicators of serioecal soils in the semi-dump zone of the Jambyl region. ISJ Theoretical \& Applied Science, 05 (73), 245-248

Soi: http://s-o-i.org/1.1/TAS-05-73-34 Doi: crossef https://dx.doi.org/10.15863/TAS.2019.05.73.34

\section{УСТАНОВЛЕНИЕ ГИДРОХИМИЧЕСКИХ ПОКАЗАТЕЛЕЙ СЕРОЗЕМНЫХ ПОЧВ В ПОЛУПУСТЫННОЙ ЗОНЕ ЖАМБЫЛСКОЙ ОБЛАСТИ}

Аннотация: В статье рассматриваются гидрохимических показателей серозёмных почв полупустынной зоны. Для регулирования водно - солевого режимов в расчетном слое почвогрунта основывая опытных работ по изучению солеотдачи почв установлены промывных норм засоленных почв.

Определены гидрохимических показателей переноса солей в почвегрунте различного механического состава.

Ключевые слова: гидрохимия, водно-солевой режим почвы, гидрохимические показателей, фильтрации, промывные нормы.

\section{Introduction}

В настоящее время в мелиорации широко применяются математические модели , дающие возможность построить прогноз водно-солевого режима почвогрунтов .

Решение этой задачи требует применение физико-математических моделей, которые дают возможность для оценки содержание солей в почвах и количественного описания законов их движения и распределения в корнеобитаемом слое почвогрунтов.

Основными методами регулирования гидрохимического режима являются воздействия на уровень грунтовых вод различными мероприятиями (орошение, промывка, рыхление почв на фоне дренажа). На формирование водно солевого, теплового и пищевого режимов в расчетном слое почвогрунта непосредственно 


\begin{tabular}{|c|c|c|c|c|c|c|}
\hline \multirow{4}{*}{ Impact Factor: } & ISRA (India) & $=3.117$ & SIS (USA) & $=0.912$ & ICV (Poland) & $=6.630$ \\
\hline & ISI (Dubai, UAE & $=0.829$ & РИНЦ (Russia & $=0.156$ & PIF (India) & $=1.940$ \\
\hline & GIF (Australia) & $=0.564$ & ESJI (KZ) & $=8.716$ & IBI (India) & $=4.260$ \\
\hline & JIF & $=1.500$ & SJIF (Morocce & $=5.667$ & OAJI (USA) & $=0.350$ \\
\hline
\end{tabular}

влияют водно - физические и физико химические процессы. Это обусловлено тем, что в результате орошения и промывки с применением дренажа резко изменяются условия формирования приходных и расходных элементов водно солевого баланса, запасов солей, скорости инфильтрации, изменения передвижения влаги, испарения, оттока грунтовых вод и другие. Применение комплекса эколого - мелиоративных мероприятй позволило вытеснить выщелачиваемые токсичные соли из расчетного соля.

\section{Materials and Methods}

Определение гидрохимических показателей переноса солей в почвогрунте посвящено много работ С.Ф.Аверьянов, 1965 ; Н.Веригин, Р.Машарипов, Д.Ф.Шульгин, 1977; Н.Н.Веригин, 1953; Л.М.Рекс, 1967; Я.А.Пачевский, 1976; Э.А.Соколенко, А.А.Кавокин, 1974; Л.М.Рекс, А,Е.Якиревич, 1989; Ю.М.Денисов,1981 и др. В этих работах приводится методика нахождения одного или другого показатели переноса солей в почвогрунта,однакоследует отметить,что все они сложные и многопараметричные [1-2].

Для определения гидрохимических показателей переноса солей в почвогрунте, и для построения прогноза водно-солевого режима нами использовано основное уравнение движения солей в почвогрунте[1]:

$$
\partial \mathrm{C} / \partial \mathrm{t}=\mathrm{D} * \partial^{2} \mathrm{C} / \partial \mathrm{x}^{2} \pm \vartheta_{\phi} \partial \mathrm{C} / \partial \mathrm{x} \pm \gamma\left(\mathrm{C}_{\mathrm{H}}-\mathrm{C}\right)
$$

где С-расчетное (прогнозное ) содержание солей, г/л или \% ; t-время, сутки; Х-глубина расчетного слоя от поверхности земли, м; $\mathrm{C}_{\mathrm{H}^{-}}$предельная концентрация раствора, г/л или \%; $\gamma$ коэффициент обмена (растворение и кристализация), 1/сут; $\mathrm{D}^{*}$ - коэффициент конвекивной диффузии, м²/сут; $\vartheta_{\phi^{-}}$фактическая скорость движения влаги в почвегрунте, м/сут. Определяется по формуле:

$$
\vartheta_{\phi}=\mathrm{V} / \mathrm{n}_{\mathrm{a}},
$$

где $\vee$-скорость фильтрации, м/сут; $\mathrm{n}_{\mathrm{a}^{-}}$активная пористость почвогрунтов, в долях от обьема.

Для определения гидрохимических показателей переноса солей в почвогрунте, входящие в в уравнение (1), были использованы[2-5] :

Использованные данные, которые необходимы для проведения расчетов и полученные результаты гидрохимических показателей переноса солей в почве грунте внесены в таблицу 1.

\section{Таблица 1.Значение гидрохимических и других показателей переноса солей в почве грунте

\begin{tabular}{|c|c|c|c|c|c|c|c|}
\hline $\begin{array}{l}\text { Группа } \\
\text { почв }\end{array}$ & $\begin{array}{l}\text { Коэфф. } \\
\text { фильтр. } \\
\text { почв. } \\
\text { К }_{\phi,} \\
\text { м/сут }\end{array}$ & $\begin{array}{l}\text { Междре } \\
\text { нного } \\
\text { рассто } \\
\text { яния,R,M }\end{array}$ & $\begin{array}{l}\text { Модуль } \\
\text { дренаж. } \\
\text { стока,q, } \\
\text { л/с.га }\end{array}$ & $\begin{array}{l}\text { Исходное } \\
\text { солесодержание } \\
, \mathrm{C}_{\mathrm{n}}, \%\end{array}$ & $\begin{array}{l}\text { Допусти } \\
\text { мое } \\
\text { солесодержание } \\
\mathrm{C}_{\text {д }}, \%\end{array}$ & $\begin{array}{l}\text { Пормывные } \\
\text { нор } \\
\text { мы, } \mathrm{N}_{\text {нт, }} \\
\text { м²/га }^{3}\end{array}$ & $\begin{array}{l}\text { Продолжит } \\
\text { ельность } \\
\text { промывки, } \\
\text { t,сут }\end{array}$ \\
\hline 1 & 2 & 3 & 4 & 5 & 6 & 7 & 8 \\
\hline I & $3.2-5.0$ & 400 & 1.61 & 2.0 & 0.30 & 5000 & $35-40$ \\
\hline I I & $2.5-3.0$ & $300-400$ & 0.87 & 2.0 & 0.33 & 6000 & $70-100$ \\
\hline I I I & $1.2-2.0$ & $200-300$ & 0.77 & 2.0 & 0.36 & 8000 & $100-150$ \\
\hline IV & $0.6-1.0$ & $100-200$ & 0.64 & 2.0 & 0.40 & 10000 & $170-220$ \\
\hline $\mathrm{V}$ & $0.2-0.5$ & $50-100$ & 0.56 & 2.0 & 0.45 & 12000 & $240-280$ \\
\hline
\end{tabular} различного механического состава}

\begin{tabular}{|c|c|c|c|c|c|c|c|}
\hline $\begin{array}{l}\text { Активная } \\
\text { пористос } \\
\text { ть, } \\
\mathrm{n}_{\mathrm{a}}, \%\end{array}$ & $\begin{array}{l}\text { Параме } \\
\text { тр } \\
\text { Пекле,Р } \\
\text { е }\end{array}$ & $\begin{array}{l}\text { Скорость } \\
\text { Фильтрац } \\
\text { ии, } \quad \vee, \\
\text { м/сут }\end{array}$ & $\begin{array}{l}\text { Фактическ } \\
\text { ая } \\
\text { скорость, } \\
\vartheta_{\phi}, \text { м/сут }\end{array}$ & $\begin{array}{l}\text { Показател } \\
\text { ь } \\
\text { солеотдач } \\
\text { и, } \alpha\end{array}$ & $\begin{array}{l}\text { Коэфобмен } \\
\mathrm{a}, \beta, \\
1 / \text { сут }\end{array}$ & $\begin{array}{l}\text { Коэф. } \\
\text { конвектив.диф } \\
\text { фуз ии, D* } \\
, \text { м²/сут }^{2}\end{array}$ & $\begin{array}{l}\text { Расчетное } \\
\text { (прогнозн } \\
\text { ое ) } \\
\text { содержан } \\
\text { ие солей } \\
\text { C }_{t}, \%\end{array}$ \\
\hline 9 & 10 & 11 & 12 & 13 & 14 & 15 & 16 \\
\hline 37 & 5.3 & 0.014 & 0.038 & 0.61 & 0.053 & 0.0072 & 0.30 \\
\hline 38 & 2.2 & 0.0075 & 0.020 & 0.77 & 0.022 & 0.0088 & 0.34 \\
\hline 40 & 1.4 & 0.0067 & 0.017 & 1.08 & 0.014 & 0.012 & 0.37 \\
\hline 41 & 0.9 & 0.0056 & 0.014 & 1.43 & 0.009 & 0.015 & 0.40 \\
\hline 42 & 0.6 & 0.0048 & 0.012 & 1.85 & 0.006 & 0.019 & 0.45 \\
\hline
\end{tabular}

Продолжение таблицы 1 


\begin{tabular}{llllll} 
& ISRA (India) $=\mathbf{3 . 1 1 7}$ & SIS (USA) & $=\mathbf{0 . 9 1 2}$ & ICV (Poland) & $=\mathbf{6 . 6 3 0}$ \\
Impact Factor: & ISI (Dubai, UAE) $=\mathbf{0 . 8 2 9}$ & PUHL (Russia) $=\mathbf{0 . 1 5 6}$ & PIF (India) & $=\mathbf{1 . 9 4 0}$ \\
& GIF (Australia) $=\mathbf{0 . 5 6 4}$ & ESJI (KZ) & $=\mathbf{8 . 7 1 6}$ & IBI (India) & $=\mathbf{4 . 2 6 0}$ \\
& JIF & $\mathbf{1 . 5 0 0}$ & SJIF (Morocco) $=\mathbf{5 . 6 6 7}$ & OAJI (USA) & $\mathbf{0 . 3 5 0}$ \\
\hline
\end{tabular}

Из таблицы 1 видно, что скорость фильтрации ( $\mathrm{V})$ и Фактическая скорость движения влаги в почвогрунте $\left(\vartheta_{\phi}\right)$ уменьшается в соответствии с утяжелением механического состава. Если в легких почвах указанные показатели составляют, соответственно 0.014 и 0.0048 м/сут. ,то есть почти три раза[4-7].

Результаты подчетов показывают, что показатель Пекле значительной степени изменяется в зависимости от механического состава почвогрунтов. Значение показателя Пекле в легких почвах с особо низкой солеотдачей, снижается до 0.53 , то есть более чем в 9 раз.

Значение коэффициента конвекивной диффузии в соответствии с утяжелением механического состава почвогрунтов увеличивается . Если коэффициента конвекивной диффузии в легких почвах составляют :0.0072$0.088 \mathrm{~m}^{2} /$ сут. то в тяжелых доходит 0.015-0.019 $\mathrm{M}^{2} /$ сут. то есть в зависи мости от механического состава почвогрунтов увеличивается в 2.6 раза.

Как исследования показывают, что основной целью опытных работ по изучению солеотдачи почв явилось обоснование промывных норм засоленных почв. Промывная норма для опреснения расчетного слоя почвы определяется по В.Р.Волобуеву по следующей формуле[2-4]:

$$
\mathrm{N}=\mathrm{K} . \alpha \lg \mathrm{S}_{\mathrm{H}} / \mathrm{S}_{\mathrm{t}} \text {, }
$$

где $\mathrm{N}$-промывная норма , $\mathrm{M}^{3} /$ га; $\alpha$-параметр солеотдачи почв; $\mathrm{S}_{\mathrm{H}}$-исходное засоление почв, \%; $\mathrm{S}_{\mathrm{t}}$, -остаточное засоление , \%; К-коэффициент пропорциональности ,равный 10000.Из формулы (3) :

$$
\alpha=\mathrm{N} / \mathrm{K} \lg \mathrm{S}_{\mathrm{H}} / \mathrm{S}_{\mathrm{t}},
$$

Ниже приводим таблицу определялалось по формуле 2, где (4), по данным наших опытных работ.Величина $\alpha$ зависит от многих факторов :от количество солей, от типа засоления, от водопроницаемости почвогрунтов и др.По нашим исследованиям при промывке почв нормой от 4000 до $8000 \mathrm{~m}^{3} /$ га величина $\alpha$ колеблется от 1.31 до 3.51 . Низкое значения (1.28 -1.31) у почв опытных площадек 1,2,3(Таблица 2).Это обьясняется тем ,что водопоницаемость почв перечисленных площадей очень низкая.Как уже говорилось выше в первой площадке для впитывания нормы 4000 $\mathrm{m}^{3} /$ га потребовалось 680 часов времени, во второй площадке для впитывания $8000 \mathrm{~m}^{3} /$ га воды 610 часов, а в третьей площадке для впитывания нормы $10000 \mathrm{~m}^{3} /$ га -520 часов.Как известно, чем ниже водопроницаемость, то есть скорость движения воды в почвенных порах , тем больше солей растворяются в единице обьема воды. Низкой водопроницаемости почв способствует химизм засоления (натриевый тип засоления катионногосостава и участие соды в анионном составе). Известно, что соли натрия, особенно сода $\left(\mathrm{Na}_{2} \mathrm{CO}_{3}\right)$, диспергирующие действует на почву, в результате чего происодит набухание почвенной массы, которое приводит к сужению активных пор.

Для почв опытной площадки №2, №4, имеющей больший параметр солеотдача $\alpha(1.28$ 3.51), характерна высокая водопроницаемость. Для впитывания нормы $10000 \quad \mathrm{~m}^{3} /$ га воды потребовалось всего 24 часов времени. Такая высокая водопроницаемость,обьясняется по нашему мнению, отсутствием соды в исходном засоления почвы и не появлением ее в ходе промывок. Низкой солеотдачи почв способствует так же присутствие в почве значительная количества труднорастворимой соли -гипса $\left(\mathrm{CaSO}_{4}-0.48 \%\right)$.

\begin{tabular}{|c|c|c|c|c|c|c|}
\hline Название почв & Тип засоления & $\begin{array}{l}\mathrm{N}_{\text {нт, }} \\
\mathrm{M}^{3} / г \mathrm{a}\end{array}$ & $\mathrm{S}_{\mathrm{H}}, \%$ & $\mathrm{~S}_{\mathrm{t}}, \%$ & $\lg S_{H} / S_{t}$ & $\alpha$ \\
\hline \multirow{3}{*}{$\begin{array}{l}\text { Солончак } \\
\text { луговой }\end{array}$} & \multirow{3}{*}{$\begin{array}{l}\text { Хлоридно- } \\
\text { сульфатный }\end{array}$} & 2000 & 0.95 & 0.70 & 0.133 & 1.5 \\
\hline & & 4000 & 0.95 & 0.47 & 0.305 & 1.31 \\
\hline & & 6000 & 0.95 & 0.40 & 0.376 & 1.60 \\
\hline \multirow{4}{*}{$\begin{array}{l}\text { Лугово-сероземная } \\
\text {,Сильнозасоленная }\end{array}$} & \multirow{4}{*}{$\begin{array}{l}\text { Хлоридно- } \\
\text { Сульфатный,с } \\
\text { учасием соды }\end{array}$} & 2000 & 1.86 & 1.30 & 0.156 & 1.28 \\
\hline & & 4000 & 1.86 & 1.20 & 0.190 & 2.11 \\
\hline & & 6000 & 1.86 & 1.18 & 0.198 & 3.03 \\
\hline & & 8000 & 1.86 & 1.10 & 0.228 & 3.51 \\
\hline \multirow{3}{*}{$\begin{array}{l}\text { Лугово-сероземная } \\
\text {,Сильнозасоленная }\end{array}$} & \multirow{3}{*}{$\begin{array}{l}\text { Сулфатно- } \\
\text { Хлоридный,с } \\
\text { учасием соды }\end{array}$} & 2000 & 1.44 & 1.20 & 0.079 & 2.53 \\
\hline & & 4000 & 1.44 & 1.08 & 0.125 & 3.20 \\
\hline & & 6000 & 1.44 & 0.78 & 0.266 & 2.26 \\
\hline
\end{tabular}

Таблица 2. Определение параметра солеотдачи почвы 


\begin{tabular}{|c|c|c|c|c|c|c|}
\hline \multirow{4}{*}{ Impact Factor: } & ISRA (India) & $=3.117$ & SIS (USA) & $=0.912$ & ICV (Poland) & $=6.630$ \\
\hline & ISI (Dubai, UAI & $=0.829$ & РИНЦ (Russia & $=0.156$ & PIF (India) & $=1.940$ \\
\hline & GIF (Australia) & $=0.564$ & ESJI (KZ) & $=8.716$ & IBI (India) & $=4.260$ \\
\hline & JIF & $=1.500$ & SJIF (Morocce & $=5.667$ & OAJI (USA) & $=0.350$ \\
\hline
\end{tabular}

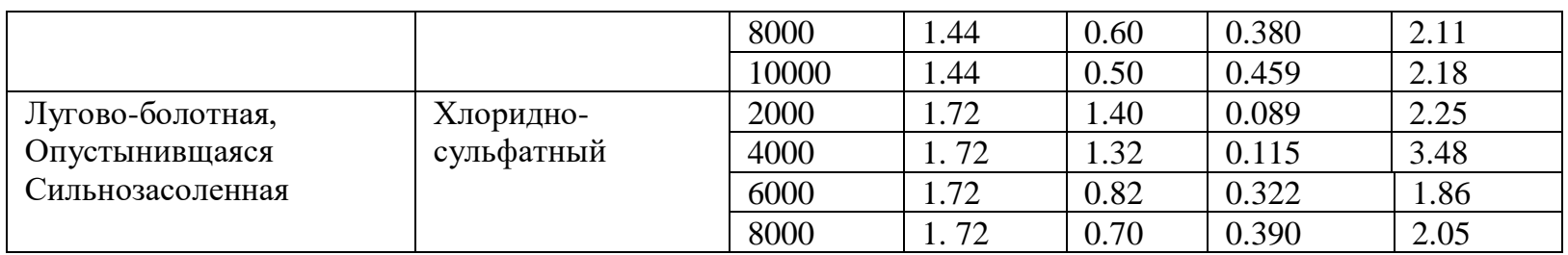

\section{Выводы.}

Результаты исследования опытного участка показывают, что значение гидрохимических и других показателей(коэффициентов обмена, конвективной диффузии, и.др) переноса солей в почвегрунте различного механического состава, а также установления параметра солеотдачи почвы в различных типах засоленности почвогрунтов, для обеспечения необходимых данных при получения урожайности сельскохозяйственных культур исследуемого массива оршения.

\section{References:}

1. Aver'yanov, S. F. (1978). Bor'ba s zasoleniem orshaemykh zemel'. (p.288). Moscow.

2. Volobuev, V. R. (1975). Raschet promyvki zasolennykh pochv. (p.71). izdat. Kolos.

3. Seytkaziev, A. S. (2000). Opredelenie promyvnykh normy // Nauki i obrazovanie Yuzhnogo-Kazakhstana, №21, pp.20-22.

4. Seytkaziev, A. S. (2013). Kompleks meliorativnykh meropriyatii $i$ modelirovanie peronosa soley na zasolennykh pochvakh/l Materialy Mezhdunarodn.nauchno-prakt.konf. (Kostyakovskie chteniya). (pp.82-86). Moscow: VNIIGiM.

5. Seyitkaziev, A. S. (2010). Sugarmaly geoekozhyyelerdegi tyzdangan topyraķtył sutyz almasuy. (pp.294-278). M.Kh.Dulati atyndaғy TarMU, Taraz.

6. Seytkaziev, A. S., \& Budantsev, K. L. (2002). Modelirovanie vodno-solevogo rezhima pochv na zasolennykh zemlyakh//Mezhvuzov. Sb.nauchn.trudov. (pp.72-79). Moscow.

7. (1979). Spravochnoe rukovodstvo gidrogeologa, tom 1. (p.512). izdat. Nedra.

8. Seytkaziev, A. S. (2013). Pochvennoekologicheskaya otsenka zasolennykh zemel'v usloviyakh aridnoy zony. Materialy mezhdunarodn.nauchno-prakt. Konf. «Melioratsiya v Rossii -traditsii i sovremennost'» posvyashchena 110-letiyu S.F.Aver'yanova. (pp.162-170). Moscow.

9. Seytkaziev, A. S., \& Budantsev, K. L. (2002). Modelirovanie vodno-solevogo rezhima pochv na zasolennykh zemlyakh. Mezhvuzov. Sb.nauchn.trudov. (pp.72-79). Moscow.

10. Seitkaziyev, A., Maymekov, Z., Andasbayev, Y., \& Jetimov, M. (2016). Methodic Aspects of soils Contamination Assessmtnt of the Almatiy Region, the Recpuplic of Kazaakhstan// WALLA journal 32(1): 29-33. 